\title{
РАЗВИТИЕ МАССОВОГО СТРОИТЕЛЬСТВА КАК ФАКТОР ПОВЫШЕНИЯ КАЧЕСТВА ЖИЗНИ НАСЕЛЕНИЯ
}

\author{
(c) 2020 Валеев Эмиль Рамилевич \\ доцент кафедры управления человеческими ресурсами \\ Института управления, экономики и финансов \\ Казанский (Приволжский) федеральный университет, Россия, Казань \\ E-mail:emilv@mail.ru \\ (c) 2020 Салахова Зарина Ринатовна \\ ассистент кафедры управления человеческими ресурсами \\ Института управления, экономики и финансов \\ Казанский (Приволжский) федеральный университет, Россия, Казань \\ E-mail: zarinasalakhova@mail.ru \\ ( 2020 Пелипенко Владимир Георгиевич \\ аспирант кафедры управления человеческими ресурсами \\ Института управления, экономики и финансов \\ Казанский (Приволжский) федеральный университет, Россия, Казань \\ E-mail: Pelipenko.Vladimir@gmail.com
}

В статье осуществляется попытка проанализировать возникновение и развитие строительства массового типового жилья в различных странах мира для повышения качества жизни населения через обеспечение его собственным жильем.

Ключевые слова: дефицит жилья, массовое строительство, типовое жилье, индустриализация, государственное вмешательство, социальная политика, качество жизни населения.

Согласно существующим определениям качества жизни населения одним из его важнейших элементов является обеспеченность населения жильем. Социально-экономическая политика большинства стран мира направлена на повышение качества жизни населения, одно из направлений которой - развитие программ жилищного строительства. В настоящее время более половины населения мира живет в городах и по прогнозам ООН рост городов продолжится и дальше, так к 2050 году количество людей, проживающих в городах, достигнет 68\% [2]. При этом история знает много примеров, когда неуправляемый рост городов приводил к экономическим, социальным, санитарноэпидемиологическим проблемам. Поэтому перед государствами во всем мире встает необходимость регулирования планового процесса урбанизации, способного обеспечить устойчивый экономический рост, социально-культурное развитие и охрану окружающей среды.

Одной из целей устойчивого развития, провозглашаемых ООН, являются открытые, безопасные, жизнестойкие и устойчивые города и населенные пункты. В рамках данной цели поставлена задача - до 2030 года обеспечить всеобщий доступ к безопасному и недорогому жилью, благоустройство трущоб [7].

Для реализации поставленной задачи важно не просто построить массовое и доступное жилье, но сформировать комфортную и дружелюбную среду обитания, направленную на развитие населения. Одним из неудачных примеров массового строительства жилья является снос в 1970-х годах жилого комплекса Пруитт-Айгоу в городе Сент-Луис штата Миссури, США. Комплекс был построен в 1950-х годах с целью предоставить жилье нуждающимся, однако вместо того, чтобы стать гостеприимным зеленым районом со своей инфраструктурой, быстро превратился в гетто. Для того чтобы избежать подобных случаев в будущем важно учитывать сложившийся опыт массовой застройки и перенять наиболее удачные модели.

С середины 19 века социальный вопрос остро встал во всех индустриализирующихся странах, большая часть населения больших городов в то время жила просто в ужасающих условиях. 
Представители высшего и среднего класса считали своим долгом облегчить участь трудящихся, при этом преследуя и свои интересы - не допустить массовых протестов. Так на рубеже 19-20 веков в европейских странах стали возникать объединения, отстаивающие необходимость социальной поддержки, и вводились соответствующие программы помощи нуждающимся, финансируемые государством.

В 1873 году в Германии основан Союз социальной политики, в 1894 году во Франции образован Социальный музей, оба объединения отстаивали необходимость государственного вмешательства в экономические и общественные вопросы. В 1883 году было введено всеобщее медицинское страхование немецких рабочих, во Франции с 1893 года, а в Британии с 1911 года некоторые формы врачебной помощи стали предоставляться бесплатно. Одной из целей социальной политики стало обеспечение достойных условий жизни для всего населения независимо от статуса. Так в 1911 году было образовано Французское общество градостроителей, в 1914 - Британский королевский институт городского планирования.

В этот же период в архитектурных кругах появляются первые концепции спланированных городов. В Англии появляется концепция города-сада, первым описанием которого можно считать книгу английского социолога-утописта Эбинезера Говарда «Городы-сады будущего», опубликованную впервые в 1898 году. В своей книге он резко критикует хаотичный рост индустриального города, его негуманность и антисанитарию. В качестве альтернативы он предлагает небольшие города-сады с численностью до 32 тысяч человек, которые сочетали в себе все лучшее от деревень и городов. Эбинезер Говард описывает город-сад в форме круга, в центре находится парк, его опоясывают малоэтажные жилые дома с собственными участками, на периферию выносятся промышленность и сельскохозяйственные угодья [1].

Во Франции архитектор Тони Гарнье [3] предложил концепцию индустриального города, экспонированную впервые в 1904 году и опубликованную в 1917-м. Концепция разделяла город на четыре функциональных зоны: жилую, промышленную, культурно-административную и сельскохозяйственную. Протяженные комплексы построек должны были разделяться широкими свободными пространствами; предусматрива- лись также два разных уровня для транспортных и пешеходных маршрутов. Особое внимание он уделял оптимальному использованию существующего ландшафта - земного рельефа, солнца, воздуха и воды. Примечательно также, что Тони Гарнье исключил из своего идеального города здания суда, тюрьмы и больницы, так как считал, что по мере совершенствования общества нужда в них отпадет. Главным строительным материалом должен был стать железобетон. Жители индустриального города по замыслу Тони Гарнье должны обитать в модульных бетонных домах. Фактически этим постулатом он предсказал типовую застройку, осуществленную впоследствии во многих странах мира [3].

Помимо социального вопроса еще одной предпосылкой развития массового строительства жилья является индустриализация строительства. Здания, построенные индустриальным методом, имеют два существенных отличия от традиционного способа: во-первых, они собираются из заранее произведенных на заводе частей; во-вторых, строят их целыми партиями. Фактически это процесс автоматизации, которая увеличивает производительность за счет серийности и стандартизации [6]. В Германии и Франции архитекторы Вальтер Гропиус, Людвиг Мис ван дер Роэ, и Ле Корбюзье говорили о том, что строительство жилья традиционном методом не способно обеспечить домами всех людей, хлынувших из деревень в города. Необходимы были новые, более производительные методы. В этом плане индустриализация и типовое массовое строительство представлялось им веянием времени [6].

Первые образцы типового массового жилья стали появляться в мире в период между Первой и Второй мировыми войнами. В 1924 году в Берлине градостроителем Мартином Вагнером был построен первый в истории жилой комплекс из готовых панельных элементов. Впоследствии Вальтер Гропиус строит в Дессау образцовый район Тертен (1926-1928), Мартин Вагнер совместно с Бруно Таутом - район Хуфайзен (1925-1931) в Берлине. Большое влияние на эти проекты оказала английская концепция города-сада, определяющая тесную взаимосвязь природы с городом. Одними из самых успешных проектов того времени можно называют жилые комплексы Эрнста Мая. Он возглавлял с 1925 по 1930 год муниципальный отдел по строительству жилья во Франкфурте-на-Майне и по- 
строил серию домов в пригородах Праунхейм, Вестхаузен, Борнхейм, Ремерштадт и др. Эти пригороды-спутники были первыми примерами жилой застройки целых районов и широкого применения готовых бетоных деталей.

В СССР первые шаги в развитии массового типового жилья были сделаны Моисеем Гинзбургом, который в 1928 году возглавил секцию типизации Стройкома РСФСР, где разрабатывались модульные жилые дома из промышленных стройматериалов. Гинзбург построил в Москве жилые дома для сотрудников Госстраха (19261927) и Наркомфина (1928-1930), эти дома стали воплощением идей о типовой архитектуре. Архитекторы Андрей Буров и Борис Блохин из совершенствованием технологии строительства из готовых блоков, а Николай Ладовский предлагал строить здания, используя собранные на производстве готовые жилые ячейки.

Во Франции одним из самых ярких приверженцев массовой типовой застройки можно архитектора Ле Корбюзье, он начал экспериментировать с модульными домами различного типа еще в конце Первой мировой войны. Он разработал типовой проект двухэтажного здания Мезон Ситроен (1920-1922) и знаменитый План Вуазен (1925) [4]. Согласно плану Вуазен Ле Корбюзье предлагал снести большую часть Парижа и разбить на этой части парк с разбросанными модульными многоэтажными домами. Ле Корбозьюе, как и Эбинезер Говард с концепцией «город-сад» и Тони Гарнье с «индустриальным городом», выступает за полную реструктуризацию городов с помощью планирования и строгого порядка, только с помощью этих инструментов, по его мнению, можно спасти крупные города от грязи и хаоса. В 1933 году Ле Корбюзье подготовил Афинскую хартию - документ, провозглашающий новые принципы и цели градостроительства, подготовленный на основе изучения опыта планировки и застройки 33 крупнейших городов мира. Одним из основных предложенных им принципов является четкое разделение города на функциональные зоны: жилые массивы, промышленная (рабочая) территория, зона отдыха и транспортная инфраструктура. В своем труде Ле Корбюзье также отмечает, что единственным целесообразным тип жилья является - «свободно расположенный в пространстве многоквартирный блок» [4]. В начале 1930-х вокруг Парижа появились первые вдохновленные этими идеями жилые массивы:
Плесси-Робинсон (1924-1939) по проекту Мориса Пейре-Дортая, Жана Демэ и Жана Фестока, и Ла Мюетт (1931-1934) Марселя Лодса и Эжена Бодуана.

Первые примеры массовой застройки в Британии также относятся к 1930-м годам. Бертольд Любеткин - эмигрант из России, одним из первых в Лондоне построил многоэтажный жилой дом Хайпоинт Уан (1933-1935). В качестве примеров можно также отметить ансамбль из шести жилых домов Пуллман Корт в южном Лондоне (1936) Фредерика Гибберда и комплекс муниципального жилья Куорри Хилл (1938, снесен в 1978-м) Ричарда Ливетта, расположенный в Лидсе.

В США первая массовая застройка также начинается в 1930-е годы. Толчком послужил «Новый курс» президента Рузвельта, принятый в связи с необходимостью преодоления последствий Великой депрессии. Огромное количество людей оставшихся без жилья и работы приводит к необходимости усиления роли государства в обеспечении американцев жильем. Первые проекты, финансируемые государством, появляются в Нью-Йорке: здания Ферст Хаузиз (1934) в Нижнем Ист-сайде и Харлем Ривер Хаузиз (1936) - изолированные от улицы жилые комплексы.

Все эти первые проекты многоквартирных жилищных домов, конечно, не решили в то время жилищного вопроса, но были свидетельством того, как менялось общество, и осознавалась необходимость государственной поддержки.

После Второй мировой войны дефицит жилья еще больше возрос, и в общественном мнении усугубилась идея о необходимости массовой застройки, финансируемой государством, и типовые проекты многоквартирных домов уверенно зашагали по планете.

В это время объемы массового жилого строительства достигли своего максимума, никакие другие архитектурные сооружения не могли сравниться с ним по распространенности. Практически во всех уголках мира возводились стандартизированные «коробки и башни» [6]. Провозглашенное право на жилье распространилось значительно быстрее, чем демократия, свобода слова или расовое равноправие.

В Европе использование готовых конструкций позволило восстановить лежащий в руинах континент после Второй мировой войны. Возводимое жилье стало значительно выше и отли- 


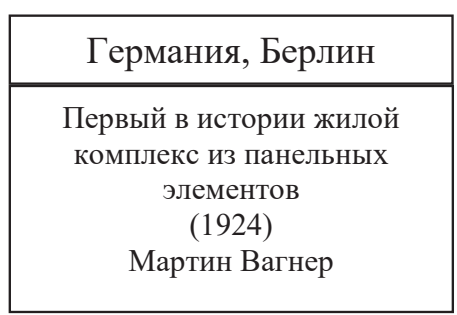

\begin{tabular}{|c|}
\hline Англия, Лондон \\
\hline Многоэтажный жилой дом \\
Хайпоинт Уан \\
(1933-1935) \\
Бертольд Любеткин \\
\hline
\end{tabular}
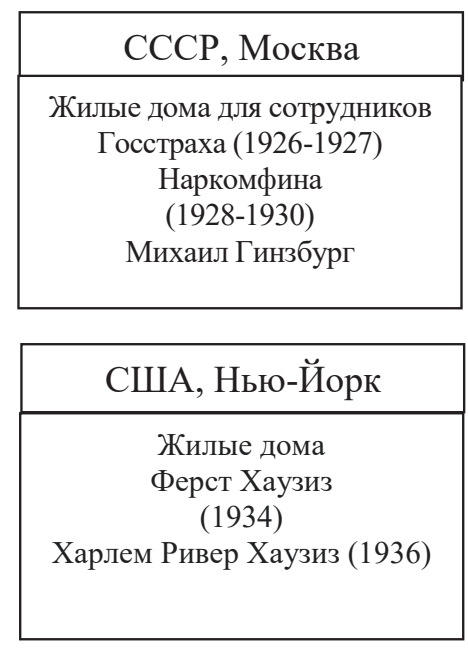

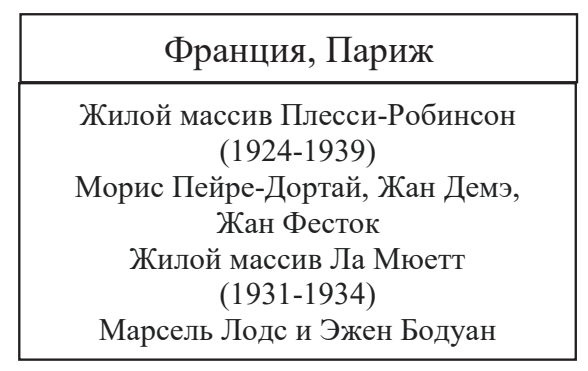

Марсель Лодс и Эжен Бодуан

\section{Puc. 1. Первые проекты массового жилья}

чалось большей плотностью. В Англии отметка в 10 этажей была достигнута в 1948 году. Среди знаменитых примеров - комплекс Черчилль Гарденс (1946) в Лондоне архитекторов Филлипа Пауэлла и Идальго Мойи и первая в Британии многоквартирная башня Лон (1950) в Харлоу, построенная Фредериком Гиббердом. В Германии были построены шестнадцатиэтажные дома Вонхоххойзер ам Гриндельберг (1946). Франция начала строительство массовой жилой застройки за счет государственных средств в 1951 году, установим «зоны приоритетной урбанизации», где должны были возводиться высотные модульные здания. В качестве примера можно привести Сите де Катр-Миль (1957) под Парижем. Особых успехов в строительстве массового жилья достигла Швеция, так с 1965 по 1974 год там реализовывалась грандиозная «Программа миллион», которую правящая Социал-демократическая партия определяла как путь к государству всеобщего благоденствия. Так в стране с менее чем девятью миллионами жителей появилось более миллиона жилищ.

Индустриальное строительство получило особенное распространение в Советском Союзе и восточноевропейских союзниках. В 1953 году Н.С.Хрущев объявил о переводе строительной отрасли на индустриальные рельсы, в 1955 году принято постановление Центрального комитета КПСС и Совета министров СССР «Об устранении излишеств в проектировании и строительстве», положившее начало советскому минимализму, типовому проектированию, увеличению эко- номичности и скорости строительства*. В 1956 году на XX съезде КПСС была поставлена задача ликвидировать жилищный дефицит за 20 лет. Так началось масштабное массовое строительство, за период 1957-1970 годов было построено более 400 млн. кв.м пятиэтажек. Плановая экономика обеспечивала идеальные условия для развития стандартизации и огромных объемов производства. Схожая ситуация развивалась и в Венгрии, Польше, Восточной Германии.

Следует отметить, что, несмотря на железный занавес и разворачивавшуюся холодную войну, был распространен обмен опытом между странами в отношении методов и принципов массового строительства. Так, в 1954 году делегация французских архитекторов посетила ГДР, после чего восточногерманские архитекторы отправились в ознакомительный тур по Франции, в ходе которого ознакомились в частности с Жилой единицей Ле Корбюзье в Марселе. В конце 1950-х годов для развития строительной отрасли СССР были закуплены 2 линии по производству бетонных панелей у французской компании Camus. Присутствовал также обмен опытом между Европой и другими континентами, к примеру, еще в 1952 году советские инженеры были приглашены в Китай, а японский архитектор Кисе Курокава много путешествовал по СССР в начале 1950-х.

В США примерами массовой застройки того времени являются построенные за счет государственных средств высотные жилые комплексы, которые вскоре стали домом для самых бедных

\footnotetext{
* Постановление ЦК КПСС и СМ СССР № 1871 «Об устранении излишеств в проектировании и строительстве».
} 
слоев населения - Пруитт-Айгоу Хоумз (19511956, снесен с 1970 по 1976), в Сент Луисе и Роберт Тейлор Хоумз (1959-1962, снесен с 1993 по 2007) в Чикаго.

Однако не во всех странах массовое жилье предназначалось для самых бедных, так в Иране в 1964 году принят закон, поддерживающий частные инвестиции в строительство многоквартирных домов высотой более десяти этажей. В Тегеране были построены высотки - БехджатАбад (1965-1968), Шахрак-е Экбатан (1970-е), которые стали домами для самых привилегированных слоев населения. После Иранской революции 1979 года исламские власти поощряли строительство башен и для бедного населения, однако, так как спрос резко превышал предложение, жизнь в высотных многоэтажках, так и осталась предметом роскоши.

Коммунистические власти Китайской Народной Республики вслед за советскими властями поддерживали идеи массовой застройки, однако до 1970-х особых успехов на этом поприще достигнуть не удалось. В последующее десятилетие Китай все больше вкладывал в массовую жилую застройку, и к 1990-м годам она стала наибольшей частью государственной градостроительной политики.

Другие азиатские страны, например, Сингапур или Южная Корея быстрее осваивали новые принципы домостроения. Так, Сингапурский Совет по развитию и жилью запустил широкомасштабную программу строительства жилья в 1960 году. С 1960 по 1965 год было построено порядка 118000 новых жилищ, в основном это были квартиры в высотных зданиях. Массовое строительство шло совместно с масштабным сносом трущоб. К 2000 году 85\% населения Сингапура живет в многоквартирных высотных домах, построенных Советом по развитию и жилью.

Южная Корея также вложила очень много средств в строительство многоэтажных жилых домов. В начале 1970-х они составляли лишь 4\% всего жилищного фонда, а к концу столетия уже более половины. За этот период доля индивидуальных жилы домов уменьшилась с 90 до 25\%. Следует отметить, что массовое жилье в Южной Корее строилось повсеместно, а не только на периферии городов, как во многих европейских странах, и предназначалось для среднего класса. Как следствие, квартиры в многоэтажных домах (тяньжи) стали нормой городской жизни и поль- зовались большой популярностью.

Многие страны Южной Америки также следовали тренду на массовое жилое строительство. В Бразилии строительство типового жилья началось в 1930-е в период авторитарного режима Жетулиу Варгаса. А в 1956 году под руководством президента Жуселину Кубичека началось масштабное строительство целого города Бразилиа с применением принципов типового строительства, который в 1960 году был объявлен столицей.

Совсем иная ситуация сложилась в Южной Африке в период апартеида (1948-1994). Высокие идеи массового жилья как инструмента обеспечения равных возможностей на свое жилище воплощались здесь в отселении черного населения в пригороды с целью надежной изоляции от белых. Правительство застраивало огромные территории дешевыми одноэтажными бараками, которые обеспечивали минимальное качество жизни, при этом обрекая жить их в удаленных районах.

Таким образом, массовое строительство в период с 1950 по 1970 распространилось по всему миру, на всех континентах строились типовые дома, и ландшафт нашей планеты полностью изменился.

Надежды на массовое жилищное строительство были огромны: реализация права каждого человека на собственное жилье, обеспечение нового уровня жизни, развитие городов. Однако, не во всех странах они оправдались. Так в США массовая жилая застройка оказалась синонимом преступности и насилия, во Франции символом неблагополучной жизни эмигрантов.

В последующие два десятилетия государственные программы по строительству массового жилья повсеместно сворачивались. В США и Франции в 1973 году, в год нефтяного кризиса, были приняты соответствующие законы, позже и другие капиталистические страны последовали их примеру. В Восточной Европе государственное вмешательство уменьшалось при ослаблении социалистических режимов. Несмотря на это строительство типовых модульных домов продолжилось, хоть и не в таких объемах, во всем мире.

Таким образом, массовая жилая застройка была ответом на вызов своего времени и позволила миллионам человек обрести свое собственное жилище, дальнейшая же ее история - успешная или нет, была вызвана множе- 
ством факторов, которые необходимо учитывать при новых программах строительства.

Мы согласны с мнением Фахрутдиновой Е.В. [8-10], что реализация программ массового жилья с целью повышения качества жизни населения основывалась в большинстве стран на ипотечном кредитовании и развитии социальных программ. В каждой из индустриальных стран мира обеспечение граждан жильем является одной из приоритетных задач. Основной инструмент решения этой задачи - ипотечное кредитование [9, с.74].

В России для решения данной задачи создаются и реализуются государственные программы по повышению уровня обеспеченности населения России жильем - «Доступное и комфортное жилье - гражданам России» (2006-2010 гг.), «Обеспечение доступным и комфортным жильем и коммунальными услугами граждан РФ» и «Доступная среда на 2011-2020 гг» (2011-2020 гг.), «Жилье и горожская среда» (2018-2024 гг.).

\section{Библиографический список}

1. Авакян Д. А. Города-сады будущего как социально-политический проект рубежа 19-20 вв/ Вестник Московского университета. Серия 12: Политические науки.-2014.- с. 82-88.

2. Всемирный день городов// Сайт ООН / Режим доступа https://www.un.org/ru/observances/cities-day свободный (дата обращения 11.09.2020)

3. Тони Гарнье // Мастера архитектуры. Крупнейшая в мире подборка известных архитекторов/ Режим доступа https://www.architime.ru/architects/a_tony_garnier.htm свободный (дата обращения 11.09.2020)

4. Ле Корбюзье. Архитектура XX века// Режим доступа http://corbusier.totalarch.com/download/1 свободный (дата обращения 11.09.2020)

5. Постановление ЦК КПСС и СМ СССР № 1871 «Об устранении излишеств в проектировании и строительстве»// Документ, который изменил всё. Главное о постановлении «об устранении излишеств...»/ Режим доступа https://strelkamag.com/ru/article/dokument-kotoryi-izmenil-vsyo свободный (дата обращения 16.09.2020)

6. Урбан Ф. Башня и коробка: Краткая история массового жилья/ Пер.с англ. M.: Strelka press, 2019.-296с.

7. Целив областиустойчивогоразвития//СайтООН/Режимдоступа https://www.un.org/sustainabledevelopment/ $\mathrm{ru} / \mathrm{cities/} \mathrm{свободный} \mathrm{(дата} \mathrm{обращения} \mathrm{11.09.2020)}$

8. Фахрутдинова Е.В.Практика реализации национальных программ в сфере жилищного строительства// Вестник Московского университета МВД России. 2008. № 6. С. 104-107.

9. Фахрутдинова Е. В. Зарубежный опыт реализации национальных программ в сфере жилищного строительства// Экономические науки. 2008. № 49. С. 74-78.

10. Фахрутдинова Е.В. Качество жизни населения в системе социально-экономических отношений (институциональный подход) // диссертация на соискание ученой степени доктора экономических наук / Казанский финансово-экономических институт. Казань, 2010.-420с. 